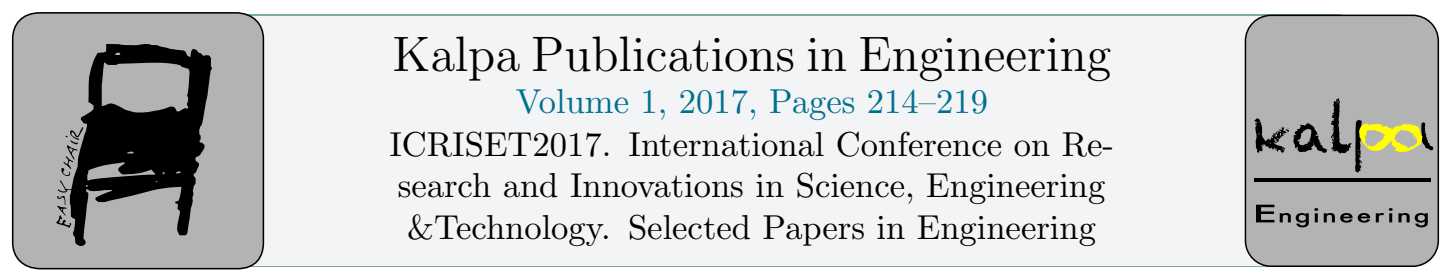

\title{
Analysis of Field Oriented Control Strategy for Induction Motor
}

\author{
Ujash V. Vachhani ${ }^{1}$ and Ashish R. Patel ${ }^{2}$ \\ ${ }^{1}$ M.Tech. Electrical Engineering, ${ }^{2}$ Asst Prof., Electrical Department \\ ${ }^{1,2}$ BVM Engineering College, Vallabh Vidyanagar, India. \\ ujashvachhani4592@gmail.com, ashish.patel@bvmengineering.ac.in
}

\begin{abstract}
This paper presents the controlling of the Induction Motor by using the 'Field Oriented Control (FOC)' method with a PI controller. In addition, the paper describes a model of three phase Induction Motor in d-q reference frame theory and its computer simulation in MATLAB/SIMULINK ${ }^{\circledR}$. The required equations are stated in the paper itself in d-q model theory.
\end{abstract}

\section{Introduction}

The Induction Motor is widely used in so many industries because of its advantages such as, ruggedness, less requirement of maintenance, low cost \& weight compared to the DC motors. It is difficult to control the induction motor and to have high stating torque like in DC motors. Therefore, the control of Induction Motor is a critical issue, especially for the applications where variable speed control is required, like Electric Vehicle.

The Induction Motor control includes many methods. A well-known method Field Oriented Control is introduced in this paper.

In a variable speed drive, the transient performance of an Induction Motor is considered. The dynamic preface of Induction Motor in the $\mathrm{d}$-q frame is important for transient performance of Induction Motor particularly for computer simulation observation in MATLAB/ SIMULINK.

The equations in d-q reference frame theory to develop the IM model in simulink are as follows [1], [2], [3].

Three phase voltages supplied to the motor are as follows,

$$
\begin{aligned}
& V_{a s \mathrm{t}}=V_{m} \sin \left(\omega_{e \mathrm{i}} t\right) \\
& V_{b s \mathrm{t}}=V_{m} \sin \left(\omega_{\mathrm{ei}} t-2 \Pi / 3\right) \\
& V_{c s \mathrm{t}}=V_{m} \sin \left(\omega_{e \mathrm{i}} t+2 \Pi / 3\right)
\end{aligned}
$$




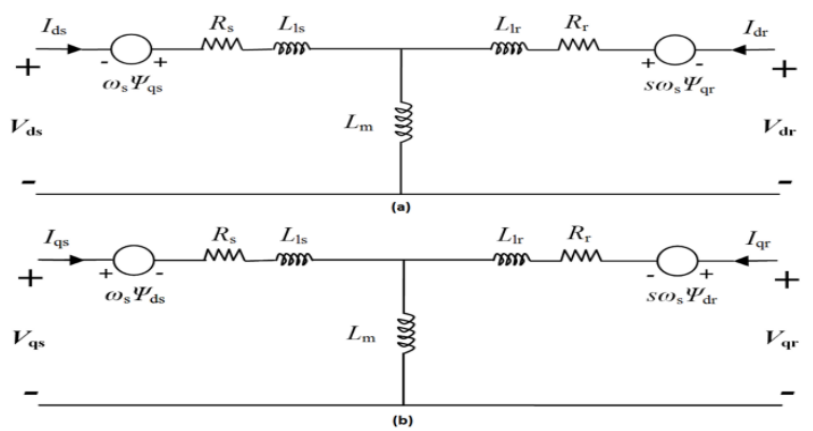

Figure 1: d-q model of IM [1]

Stationary reference frame variables of three phase $\left(V_{a s}, V_{b s}, V_{c s}\right)$ are to be transformed into stationary reference frame variables of two phase $\left(v^{s}{ }_{\mathrm{q} s}, v_{\mathrm{ds}}^{s}\right)$. This is done by following equations.

$$
\begin{aligned}
v_{\mathrm{q} s}^{\mathrm{s}} & =V_{a s \mathrm{t}} \\
v_{\mathrm{d} s}^{\mathrm{s}} & =-(1 / 1.73) V_{b s t}+(1 / 1.73) V_{c s t}
\end{aligned}
$$

Then the stationary reference frame variables of two phase $\left(v^{s}{ }_{\mathrm{q}}, v_{\mathrm{d} s}\right)$ are to be transformed into synchronously rotating frame variables of two phase $\left(v_{\mathrm{q} s}, v_{\mathrm{d} s}\right)$.

$$
\begin{aligned}
& v_{q s}=v^{\mathrm{s}}{ }_{q s} \cos \theta_{e \mathrm{i}}-v_{d s}^{\mathrm{s}} \sin \theta_{e \mathrm{i}} \\
& v_{\mathrm{d} s}=v^{\mathrm{s}}{ }_{q s} \sin \theta_{e \mathrm{i}}+v_{d s}^{\mathrm{s}} \cos \theta_{e \mathrm{i}}
\end{aligned}
$$

Where, $\omega_{\mathrm{ei}}$ is the synchronous speed at which the rotating frame rotates and $\theta_{\mathrm{ei}}=\omega_{\mathrm{ei}} \mathrm{t}$ is the angle of rotating frame with respect to stationary frame.

Now let us represent both stator and rotor circuits $\left(d_{s t}-q_{s t}\right.$ and $\left.d_{r t}-q_{r t}\right)$ and their variables in a frame that is synchronously rotating ( $d_{e t}-q_{e t}$ frame). The equations of stator circuit are given as follows.

$$
\begin{aligned}
& v_{q s}^{s}=R_{s t} i^{\mathrm{s}}{ }_{q s}+\left(d \psi^{\mathrm{s}}{ }_{q s \mathrm{t}}\right) / d t \\
& v_{d s}^{\mathrm{s}}=R_{s \mathrm{t}} i^{\mathrm{s}}{ }_{q s}+\left(d \psi^{\mathrm{s}} d s \mathrm{t}\right) / d t
\end{aligned}
$$

Where, $\psi_{q s \mathrm{~s}}^{\mathrm{s}}$ and $\psi_{d s \mathrm{~s}}^{\mathrm{s}}$ are stator flux linkages of q-axis and d-axis respectively. After converting above equations to synchronously rotating $d_{\mathrm{ei}}-q_{e \mathrm{i}}$ frame, we get following equations.

$$
\begin{aligned}
& V_{q s \mathrm{t}}=R_{s \mathrm{t}} i_{q s}+\left(d \psi_{q s \mathrm{t}}\right) / \mathrm{d} t+\omega_{e \mathrm{i}} \psi_{d s \mathrm{t}} \\
& V_{d s \mathrm{t}}=R_{s \mathrm{t}} i_{d s}+\left(d \psi_{d s \mathrm{t}}\right) / d t-\omega_{e \mathrm{i}} \psi_{q s \mathrm{t}} \\
& V_{q r \mathrm{t}}=R_{r \mathrm{t}} i_{q r}+\left(d \psi_{q r \mathrm{t}}\right) / d t+\omega_{e \mathrm{i}} \psi_{d r \mathrm{t}} \\
& V_{d r \mathrm{t}}=R_{r \mathrm{t}} i_{d r}+\left(d \psi_{d r \mathrm{t}}\right) / d t-\omega_{e \mathrm{i}} \psi_{q r \mathrm{t}}
\end{aligned}
$$

The rotor actually rotates at a speed of $\omega_{\mathrm{ri}}$. Therefore the d-q axes, which are fixed on the rotor move at speed $\left(\omega_{e \mathrm{i}}-\omega_{r \mathrm{i}}\right)$ with reference to frame which is synchronously rotating. Therefore in $d_{e \mathrm{i}}-q_{e \mathrm{i}}$ frame, the actual rotor equations are written as follows.

$$
\begin{aligned}
V_{\mathrm{q} r \mathrm{t}} & =R_{r \mathrm{t}} i_{\mathrm{q} r}+\left(d \psi_{\mathrm{qrt}}\right) / d t-\left(\omega_{e \mathrm{i}}-\omega_{r \mathrm{i}}\right) \psi_{\mathrm{drt}} \\
V_{d r \mathrm{t}} & =R_{r \mathrm{t}} i_{d r}+\left(d \psi_{d r \mathrm{t}}\right) / d t-\left(\omega_{e \mathrm{i}}-\omega_{r \mathrm{i}}\right) \psi_{q r \mathrm{t}}
\end{aligned}
$$

As earlier said, in this paper, the dynamic model of induction motor in state space form is going to be developed. Therefore, it is necessary to define flux linkage variables and are given as follows 


$$
\begin{gathered}
F_{q s \mathrm{t}}=\omega_{b \mathrm{i}} \psi_{q s \mathrm{t}} \\
F_{q r \mathrm{t}}=\omega_{b \mathrm{i}} \psi_{q \mathrm{rt}} \\
F_{d s \mathrm{t}}=\omega_{b \mathrm{i}} \psi_{d s \mathrm{t}} \\
F_{d r \mathrm{t}}=\omega_{b \mathrm{i}} \psi_{d r \mathrm{t}}
\end{gathered}
$$

Where, $\omega_{b i}=$ base frequency of the machine. By substituting the relations in stator and rotor equations, we get the following equations assuming $V_{q r \mathrm{t}}=V_{d r \mathrm{t}}=0$

$$
\begin{aligned}
& V_{q s \mathrm{t}}=R_{s \mathrm{t}} i_{q s}+\left(1 / \omega_{b \mathrm{i}}\right)\left(d F_{q s t} / d t\right)+\left(\omega_{e \mathrm{i}} / \omega_{b \mathrm{i}}\right) F_{d s \mathrm{t}} \\
& V_{d s \mathrm{t}}=R_{s \mathrm{t}} i_{d s}+\left(1 / \omega_{b \mathrm{i}}\right)\left(d F_{d s \mathrm{t}} / d t\right)-\left(\omega_{e \mathrm{i}} / \omega_{b \mathrm{i}}\right) F_{q s \mathrm{t}} \\
& 0=R_{r \mathrm{t}} i_{q r}+\left(1 / \omega_{b \mathrm{i}}\right)\left(d F_{q r t} / d t\right)+\left\{\left(\omega_{e \mathrm{i}}-\omega_{\gamma \mathrm{i}}\right) / \omega_{b \mathrm{i}}\right\} F_{d r \mathrm{t}} \\
& 0=R_{r \mathrm{t}} i_{d r}+\left(1 / \omega_{b \mathrm{i}}\right)\left(d F_{d r t} / d t\right)-\left\{\left(\omega_{e \mathrm{i}}-\omega_{r \mathrm{i}}\right) / \omega_{b \mathrm{i}}\right\} F_{q r \mathrm{t}}
\end{aligned}
$$

Torque produced by motor is found by

$$
T_{e \mathrm{i}}=(3 / 2)(\mathrm{p} / 2)\left(1 / \omega_{b \mathrm{i}}\right)\left(F_{d s \mathrm{t}} i_{q s}-F_{q s \mathrm{t}} i_{d s}\right)
$$

Once the torque is found, the speed of the motor can be calculated by the equation,

$$
T_{e \mathrm{i}}=T_{L \mathrm{i}}+(2 / p) J\left(d \omega_{\mathrm{ri}} / d t\right)
$$

Based on all these equations the model of Induction Motor can be developed in simulink.

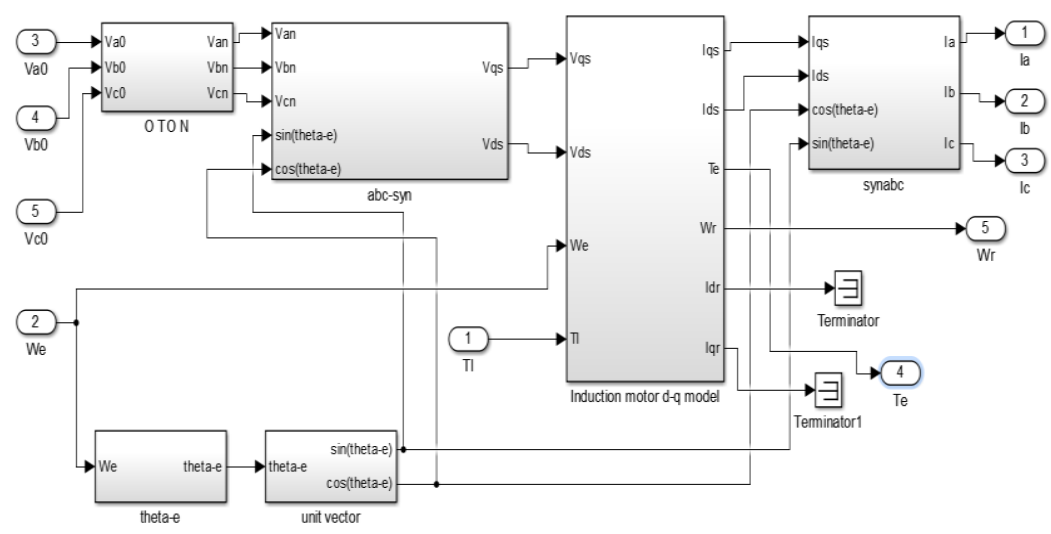

Figure 2: Simulink model of IM

\section{Field Oriented Control for 'Induction Motor'}

'Field Oriented Control (FOC)' includes control of the stator currents of motor, assigned by vectors with a d-q frame system in a reference frame, which is rotating.

The main aim of this method is to maintain the stator field and rotor field perpendicular to each other to produce the maximum torque. So that it is possible to control, directly and separately, the Induction Motor's torque and flux. 'Induction Motor Field oriented controlled' drive obtains every advantage of DC machines. For accurate transient and steady-state responses, the instantaneous control of individual quantities is done [4], [5].

There are two types of FOC method [4]. 


\subsection{Direct FOC (DFOC)}

Flux vector, in this method is to be measured by mounting a sensor in the air-gap, which senses the flux. Because of a sensor, the construction of motor becomes complex. So it is not widely used.

\subsection{Indirect FOC (IFOC)}

In this method the flux vector of the rotor is estimated by using the FOC equations.

The block diagram of FOC strategy is as shown.

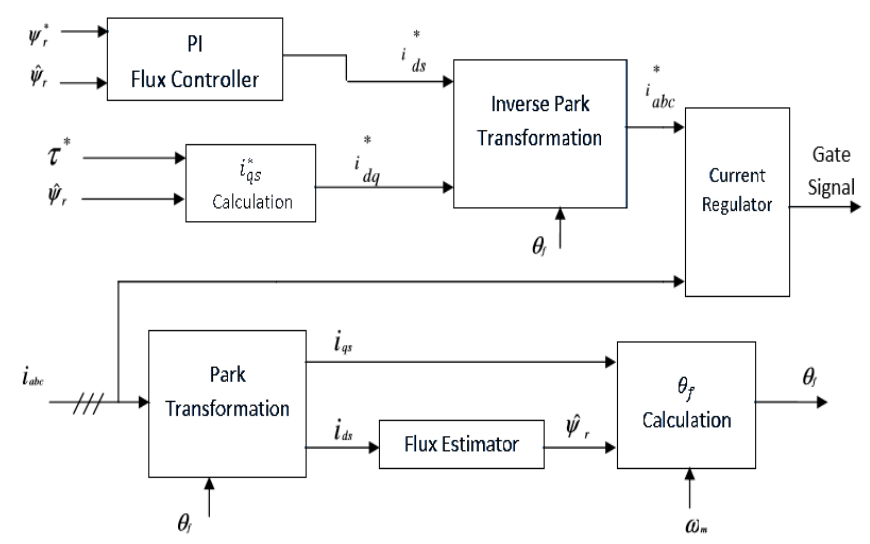

Figure 3: Block diagram of FOC [4]

\subsection{Algorithm of FOC}

The algorithm of FOC is summarized as described below [4].

1. The $i_{a}, i_{b}$ and $i_{c}$ stator currents are measured. If two values $i_{a} \& i_{b}$ are first measured than $i_{c}$ can be easily calculated from the balanced current equation $i_{a}+i_{b}+i_{c}=0$.

2. All these three phase measured currents than to be transformed into two axis frame which provides two variables those are $i_{\alpha}$ and $i_{\beta}$ in rotating two axis from the measured $i_{a}$, $i_{b}$ and $i_{c}$ which is known famously as 'Clarke Transformation'.

3. Magnitude of rotor flux and the orientation of it is to be calculated.

4. By using the transformation angle, which is calculated at the last iteration, the $i_{\alpha}$ and $i_{\beta}$ are converted in the stationary two axis components $\mathrm{i}_{\mathrm{d}}$ and $\mathrm{i}_{\mathrm{q}}$ which is known as 'Park Transformation'.

5. By using the flux reference and its estimated flux value, the flux error signal is calculated than a PI controller is used for the calculation of $\mathrm{i}_{\mathrm{d}}{ }_{\mathrm{f}}$ and $\mathrm{i}_{\mathrm{q}}{ }_{\mathrm{q}}$ is to be generated by using the reference value of torque and the estimated value of flux.

6. $\quad \mathrm{i}_{\mathrm{d}}^{*}$ and $\mathrm{i}_{\mathrm{q}}^{*}$ are then to be converted into a set of currents of three phase to produce $\mathrm{i}_{\mathrm{d}}{ }^{*}$ and $\mathrm{i}_{\mathrm{a}}, \mathrm{i}_{\mathrm{b}}$ and $i^{*}$.

7. $\mathrm{i}_{\mathrm{a}}^{*}, \mathrm{i}_{\mathrm{b}}^{*}, \mathrm{i}_{\mathrm{c}}^{*}$ are compared with $\mathrm{i}_{\mathrm{a}}, \mathrm{i}_{\mathrm{b}}, \mathrm{i}_{\mathrm{c}}$ by using hysteresis comparator in order to generate gate signals for the inverter.

Now from the above diagrams the simulink model for FOC can be developed in simulink which is shown below. 


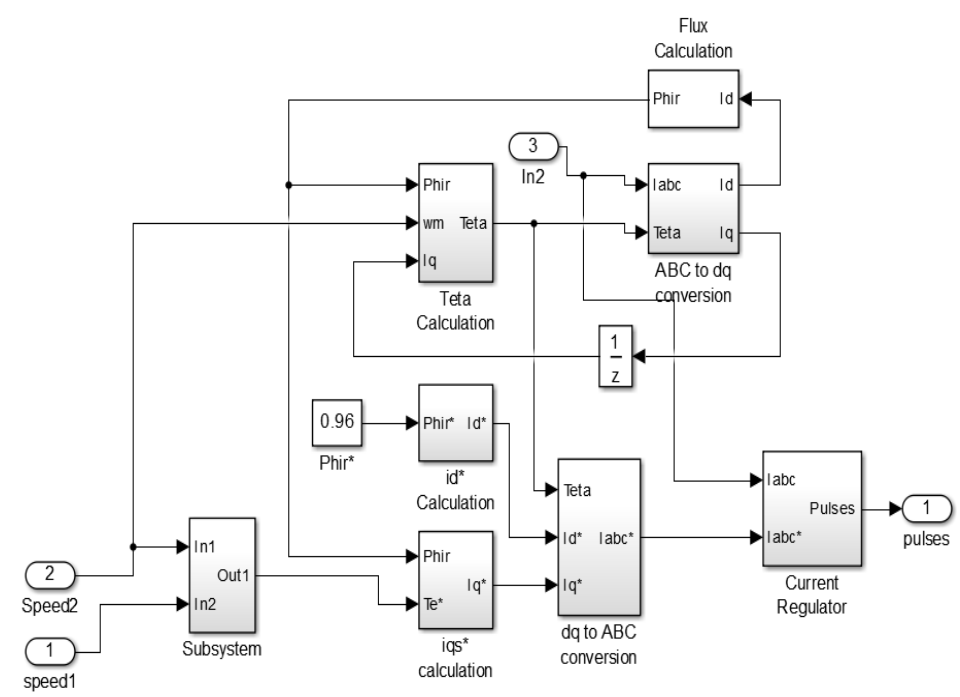

Figure 4: Simulation model of FOC

\section{Simulation Results}

\subsection{At No-load}

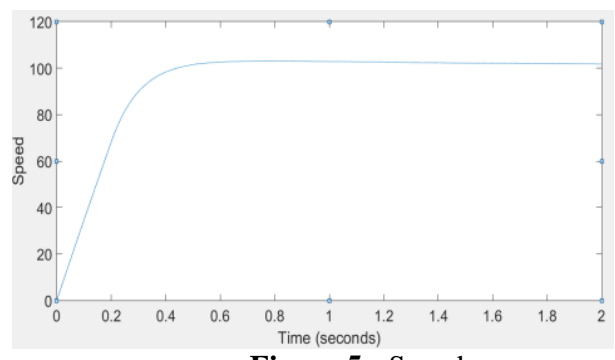

Figure 5: Speed

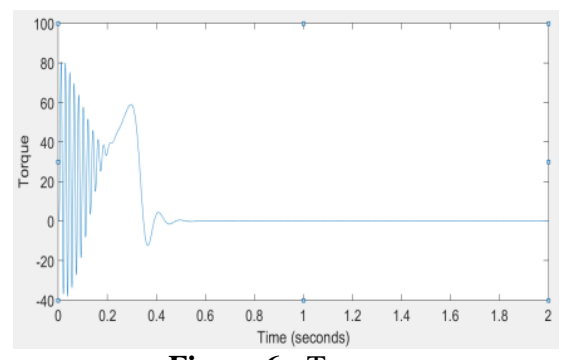

Figure 6: Torque

Fig. 5 and fig. 6 shows the speed and torque responses. At time 0.421 seconds speed is $100 \mathrm{rpm}$ and after that it remains at $100 \mathrm{rpm}$. Simultaneously the torque is oscillating between the values of +80 $\mathrm{Nm}$ and $-40 \mathrm{Nm}$ up to the speed of $100 \mathrm{rpm}$ and after that it remains at zero. From this figures we can say that IM quickly attain the speed of $100 \mathrm{rpm}$ with a stable torque condition.

\subsection{At $\mathrm{T}_{\mathrm{L}}=20 \mathrm{Nm}$}

Fig.7 and fig.8 shows the speed and torque responses. At time 0.44 seconds speed is $100 \mathrm{rpm}$ and after that it remains at $100 \mathrm{rpm}$. Simultaneously the torque is oscillating between the values of +80 $\mathrm{Nm}$ and $-40 \mathrm{Nm}$ up to the speed of $100 \mathrm{rpm}$ and after that it remains at $20 \mathrm{Nm}$. 


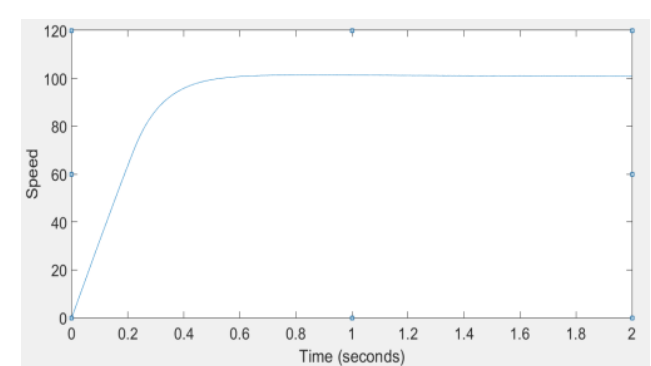

Figure 7: Speed

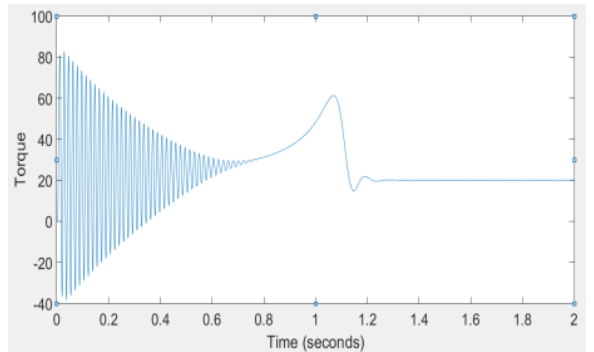

Figure 8: Torque

From the above results, we can observe the speed waveform and torque waveform (at zero). However, at load torque $\mathrm{TL}=20 \mathrm{Nm}$, the steady state time of the speed increases slightly and same is happening with torque waveform which is at $20 \mathrm{Nm}$.

\section{Conclusion}

The Induction Motor drive system, which is based on Field Oriented Control, is developed in this paper. By using FOC scheme with induction motor, high starting torque can be obtained like in DC motor. The benefits of FOC are that all the advantages of DC motor can be obtained in FOC-induction motor drive, with the default advantages of IM over DC motor, which makes the induction motor the most suitable drive for the applications where variable speed operations are necessary with fast response.

\section{Acknowledgment}

First and foremost I would like to thank the Almighty who blessed me to overcome the problems I faced while doing this work. I would also like to thank my project guide for his support towards this work. Also I would like to thank my teachers \& all dear friends of mine for their help and encouragement towards this work.

\section{References}

P. C. Krause, O. Wasynczuk, S. D. Sudhoff, "Analysis of Electric Machinery and Drive Systems", IEEE Press, A John Wiley \& Sons, Inc. Publication Second Edition, 2002.

Ashish R. Patel, "Modelling and control of DFIG", M.Tech. dissertation report, IITB, 2009

Anand Bellure, Dr. M. S. Aspalli, "Dynamic d-q model of Induction Motor using Simulink", IJETT - volume 24 Number $5^{\text {th }}$ June, 2015.

"Field Oriented Control", application note by Hamid Khan at RENESAS

Popescu M., "Induction Motor Modelling for Vector Control Purposes", Helsinki University of Technology, Laboratory of Electromechanics, Report, Espoo 2000, 144 p.

Tiecheng Sun, Jingwei Han, Deyan Gao, Sanling Xu, Ningbo Lu, "Research on Field Oriented Control system of Induction Motor based on Computer", at 2012 IEEE 7th International Power Electronics and Motion Control Conference, June 2-5, 2012, Harbin, China 